\title{
Formação de espeleotemas de sal como proposta de conscientização ambiental por meio da educação não formal em Geociências
}

\author{
SALt SPELEOTHEM GROWTH AS A PROPOSAL FOR ENVIRONMENTAL AWARENESS THROUGH NON-FORMAL EDUCATION IN GEOSCIENCES \\ Cintia F. Stumpf \& Tulio Gabriel. R. Ribeiro \\ InSTITUTO de GEOCIÊNCIAS, UnIIERSIDAde de BRAŚlLIA \\ 70910-900, BRAŚLIA, DF, BRASIL \\ E-MALL: CINTIA_STUMPF@YAHOO.COM.BR, tULIOGABRIELRR@GMAlL.COM
}

Abstract: Formal methods of teaching theoretical concepts, involving the use of textbooks, still prevail in conventional teaching in Brazil. New technologies and innovations are gaining space within schools, to captivate the attention of the modern student. Through a multidisciplinary approach, and based on the connection between formal education and the real world and nature, this paper aims to disseminate, in Portuguese, a well-known proposal for a practical experiment regarding the formation of salt speleothems, using geological concepts related to speleology. This proposa contributes to student engagement in the natural sciences, and encourages scientific thinking by setting up and observing practical experiences that develop the scientific abilities of observation and description. The experiment involves the creation a theoretical model of speleothem formation, and introduces, in an appropriate fashion, geological concepts of the formation of those rocks. This helps students to construct a conceptual framework that can be applied to several topics in the future, whether related to geology, climate or environmental sciences. The experimental approach of geoscience education produces a learning experience for students. The formation of salt speleothems can serve as a basis for students to begin to relate intrinsic concepts of geological science, such as time, space, and location.

\section{Manuscript:}

Received: VIII Simpósio Nacional de Ensino e História de Ciências da Terra / EnsinoGE0-2018. Geociências para Todos

Accepted: 14/01/2018

Citation: Stumpf C.F., Ribeiro T.G.R. 2018.Formação de espeleotemas de sal como proposta de conscientização ambiental por meio da educação não formal em Geociências. Terræ Didatica, 14(4):445-454. URL: http://www.ige.unicamp.br/terraedidatica/.

Palavras-chave: Introdução a cavernas, formação de espeleotemas, tipos de espeleotemas, dióxido de carbono, ácido carbônico.

Linha temática: Educação Ambiental, Educação para Sustentabilidade e Geoética

\section{Introdução}

A interdisciplinaridade nos parâmetros curriculares atuais é muito discutida, assim como a importância de manter a atenção dos alunos da nova geração, que se desenvolvem em um meio tecnológico e virtual, onde métodos tradicionais de educação baseado em livros e apostilas podem e devem ser revistos (Almeida et al. 2015). Neste contexto, a importância de atividades experimentais, que têm o poder de conectar os alunos em uma vivência prática dos conceitos teóricos aprendidos em sala de aula, leva a uma maior fixação do conteúdo, além de fomentar a aprendizagem do método científico desde o início da sua formação.

A contextualização dos temas abordados na escola e a conexão deles com a realidade dos alunos e do mundo que os cerca é essencial para promover a aprendizagem e instigar o interesse dos alunos nas ciências. Trazer o mundo real para a sala de aula, e explicar processos geológicos considerando as peculiaridades da escala de tempo é de suma importância para a educação em geociências (Carneiro et al. 2004).
O termo espeleologia refere-se ao estudo de cavernas e feições associadas, que envolve diversos aspectos como o meio geológico, biológico, químico, geográfico, climatológico, arqueológico, paleontológico e cartográfico (EGRIC 2011). Existem diversas definições do que é uma caverna, mas é comumente utilizada a definição de caverna como sendo qualquer espaço natural subterrâneo grande o suficiente para permitir a entrada do ser humano. Segundo Bernard Géze (1968),

"a espeleologia é a disciplina consagrada ao estudo das cavernas, sua gênese e evolução, do meio físico que elas representam, de seu povoamento biológico atual ou passado, bem como dos meios ou técnicas que são próprias ao seu estudo".

Trabalhar com aspectos espeleológicos no ensino de geociências abrange questões relevantes do ensino formal dos níveis básico ao superior. A espeleologia e as cavernas representam a oportunidade de conciliar a interação entre os meios físicos, bióticos, sócio-econômicos e culturais. Os alunos fazem parte da população que ocupa e vive no ambiente, fazem parte da natureza, explorando

\begin{tabular}{c|c|c|c|c|c}
\hline (C) Terrae Didat. & Campinas, SP & v.14 & n.4 & p. 445-454 & out./dez. 2018 \\
\hline
\end{tabular}


o meio ambiente, inclusive as cavernas, causando, muitas vezes, o impacto inerente a esta vivência. Nesse sentido, o ensino espeleológico tem um enorme potencial para contribuir para uma educação de qualidade, proporcionando uma experiência prática e experimental de conceitos multidisciplinares, além de relacionar a aprendizagem com a natureza.

Dentro das cavernas são formadas rochas específicas que criam uma beleza cênica característica e única dos ambientes subterrâneos. Estas formações são chamadas de espeleotemas, nome proposto por Moore (1952) derivado do grego onde spelaion significa caverna e thema depósito. Os espeleotemas são considerados formações geológicas importantes para entender processos da superfície da Terra no passado geológico, pois registram padrões de mudança de ambientes e climas no decorrer do tempo em que se formam (Fairchild and Baker 2012)Reflexões acerca do uso dos conhecimentos espeleológicos como recurso educativo são apresentadas por Custódio et al. (2012) em que os autores propõem o ambiente cavernícola como forma contextualizada de trabalhar sobre a fauna subterrânea, como também estimular discussões sobre preservação do meio ambiente e educação ambiental no ensino fundamental e médio. Os autores chamam a atenção para os poucos recursos disponíveis voltados a este tema, reforçando a importância da geração de material complementar para auxiliar os alunos a compreenderem o ambiente subterrâneo, demonstrando a importância de preservá-lo.

Atividade de campo para cavernas já é realizada como prática pedagógica para ensinos fundamental, médio e superior em algumas entidades escolares. Contudo, devido às despesas e complexidades de realizar atividade de campo, este recurso ainda é muito limitado considerando a realidade do ensino brasileiro, tanto público quanto privado. Neste sentido, é importante desenvolver atividades que levem o mundo das cavernas para dentro da sala de aula, quando não houver possibilidade de realizar o contrário.

Para que haja efetividade na transmissão do conhecimento formal, a interdisciplinaridade (e/ ou multidisciplinariedade) tem papel importante e muitas vezes pouco explorado (Ferreira et al. 2008). Estes autores indicam que temas relacionados às cavernas são geralmente tratados de forma específica, sendo pouco divulgados para a população e escolas no ciclo básico. Outro fator indicado pelos autores trata-se da barreira gerada pela linguagem técnica da maioria dos trabalhos deixando o conhecimento inacessível para determinados públicos, em especial o infanto-juvenil.

Materiais com guias práticos para atividades educacionais relacionadas à formação de cavernas ou espeleotemas são abundantes, principalmente em língua Inglesa (Carlsbad Caverns 2018, Hance \& Befus 2015, National Park Service 2018.). Entretanto, a disponibilidade deste tipo de material no Brasil e em idioma nativo é baixa e os materiais existentes são pouco informativos em relação aos temas de conservação e conhecimentos teóricos envolvidos.

A junção da atividade vinculada à espeleologia e à educação ambiental é uma oportunidade de diminuir os impactos negativos ao ambiente cavernícola, conduzindo o educando a uma reflexão e consequente ação, onde o aluno passa a compreender as consequências ocasionadas por seus comportamentos perante a natureza e o ambiente subterrâneo. Este tipo de educação ambiental integrada à atividade de sala de aula é necessário, pois as cavernas são ecossistemas frágeis que se formam no ritmo da escala de tempo geológica, muito mais lenta que o ritmo do impacto antrópico ao meio ambiente.

A proposta deste experimento utiliza uma forma educacional que envolva aspectos de geologia e formação de espeleotemas com o uso de imagens, atividade prática, vivência de laboratório doméstico, textos e possibilidade de atividade de campo com interação com a natureza. Contudo, mesmo na ausência da possibilidade de realizar uma atividade de campo, o experimento proposto oferece uma possibilidade de conexão do currículo escolar com o mundo real sem sair da sala de aula.

O guia proposto neste trabalho aborda informações introdutórias sobre cavernas e formação de espeleotemas e propõe atividades que ocorrem no decorrer de uma semana. Sabe-se que a simulação da formação de espeleotema de sal em aula prática como proposto neste trabalho não é uma inovação pedagógica. Este experimento é conhecido e encontrado em publicações eletrônicas. Contudo, observa-se que pouco é efetivamente explorado em escolas e atividades práticas no ensino de geociências e divulgação da espeleologia no Brasil, talvez devido à raridade de guias didáticos sobre o tema em idioma Português. Dada à facilidade de realizar tal experimento e da abrangente aplicabilidade dos conceitos teóricos e interdisciplinaridade da atividade, acredita-se ser de relevância ajudar a divulgar tal prática e incentivar a sua realização.

\begin{tabular}{c|c|c|c|c|c}
\hline (C) Terrae Didat. & Campinas, SP & v.14 & n.4 & p. 445-454 & out./dez. 2018 \\
\hline
\end{tabular}




\section{Objetivos}

O presente trabalho visa à divulgação em português, do experimento de precipitação de espeleotema. Dessa forma, são propostos temas e conceitos que podem ser explorados a partir do experimento, de forma a exercer educação ambiental e conscientização sobre a importância do ambiente cavernícola e da necessidade de preservação ambiental.

A ideia é que alunos construam um modelo de deposição mineral e formação de espeleotema utilizando uma solução concentrada de sal. À atividade pode ser desenvolvida em grupos e é necessário o acompanhamento e observação diária pelo período de uma semana.

Com esta proposta, acredita-se que os alunos aprenderão sobre o processo de formação de espeleotemas. O acompanhamento, descrição e análise dos resultados do experimento têm como objetivo introduzir a metodologia científica para os alunos. Por fim, procura-se discutir conceitos de tempo geológico, formação de cavernas e conservação ambiental.

Conceitos chaves a serem abordados por professores são: introdução a cavernas, formação de espeleotemas, tipos de espeleotemas, deposição química de minerais, dióxido de carbono, ácido carbônico, tempo de crescimento e rochas carbonáticas e evaporíticas.

\section{Materiais e Métodos}

Os materiais utilizados são descritos abaixo. Estes podem ser substituídos por outros equivalentes descritos entre parênteses.

1. vidro de relógio/placa de petri (pires de plástico ou porcelana, folha de papel alumínio);

2. colher;

3. clipes de metal (ou arruelas);

4. béqueres de mesmo volume (potes de vidro, de maionese, garrafas pet cortadas etc.);

5. Sal grosso / bicarbonato de sódio / sulfato de magnésio (carbonato de sódio, sais de banho, sal de cozinha);

6. Água quente;

7. Aproximadamente $15 \mathrm{~cm}$ de barbante;

O procedimento é simples e a montagem final é representada na figura 1 . Os passos para realização são descritos abaixo, e encontram-se ilustrados na figura 2.
1. Encher os béqueres com quantidade semelhante de água quente e posicioná-los lado a lado com o vidro de relógio entre eles (ou o prato entre eles). No caso de utilização da folha de alumínio, apenas dobrar as laterais da folha para criar uma "barreira" para o escorrimento do líquido. A função do vidro de relógio é coletar a água que pingará dos recipientes e se for o caso, servir como suporte para a precipitação de alguns cristais.

2. Adicionar o bicarbonato de sódio ou o sulfato de magnésio a ambos os béqueres até que o mesmo pare de dissolver e comece a acumular no fundo do pote, ou seja, a solução fique supersaturada.

3. Cortar o barbante em um pedaço de aproximadamente $15 \mathrm{~cm}$. O tamanho do fio de barbante irá depender do tamanho e distância entre os béqueres com água (verificar item seis).

4. Amarrar os clipes de metal em cada extremidade do barbante. Os clipes irão servir como peso para manter as pontas do barbante submersas em cada béquer.

5. Molhar o barbante completamente em água, deixando o fio completamente úmido.

6. Colocar cada extremidade do barbante dentro de cada béquer, de forma que os clipes fiquem no fundo dos recipientes. É necessário que se forme uma ondulação "barriga" no fio de barbante estendido entre os dois béqueres, e o meio do fio deve necessariamente estar abaixo do nível de água. O fio não deve tocar o vidro

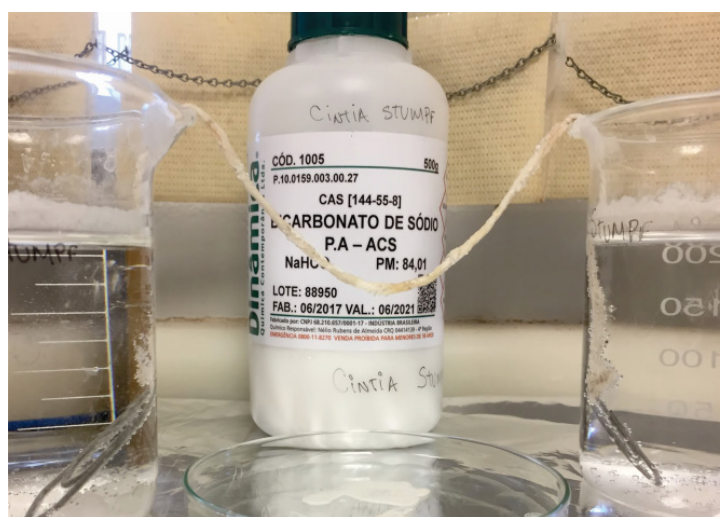

Figura 1. Montagem do experimento. Notar o pequeno espaço necessário para a montagem. 0 barbante deve estar abaixo do nível de água dos recipientes, e os pesos do barbante devem assegurar que a extremidade deste fique submersa na solução durante todo experimento

\begin{tabular}{c|c|c|c|c|c}
\hline (C) Terrae Didat. & Campinas, SP & v.14 & n.4 & p. 445-454 & out./dez. 2018 \\
\hline
\end{tabular}




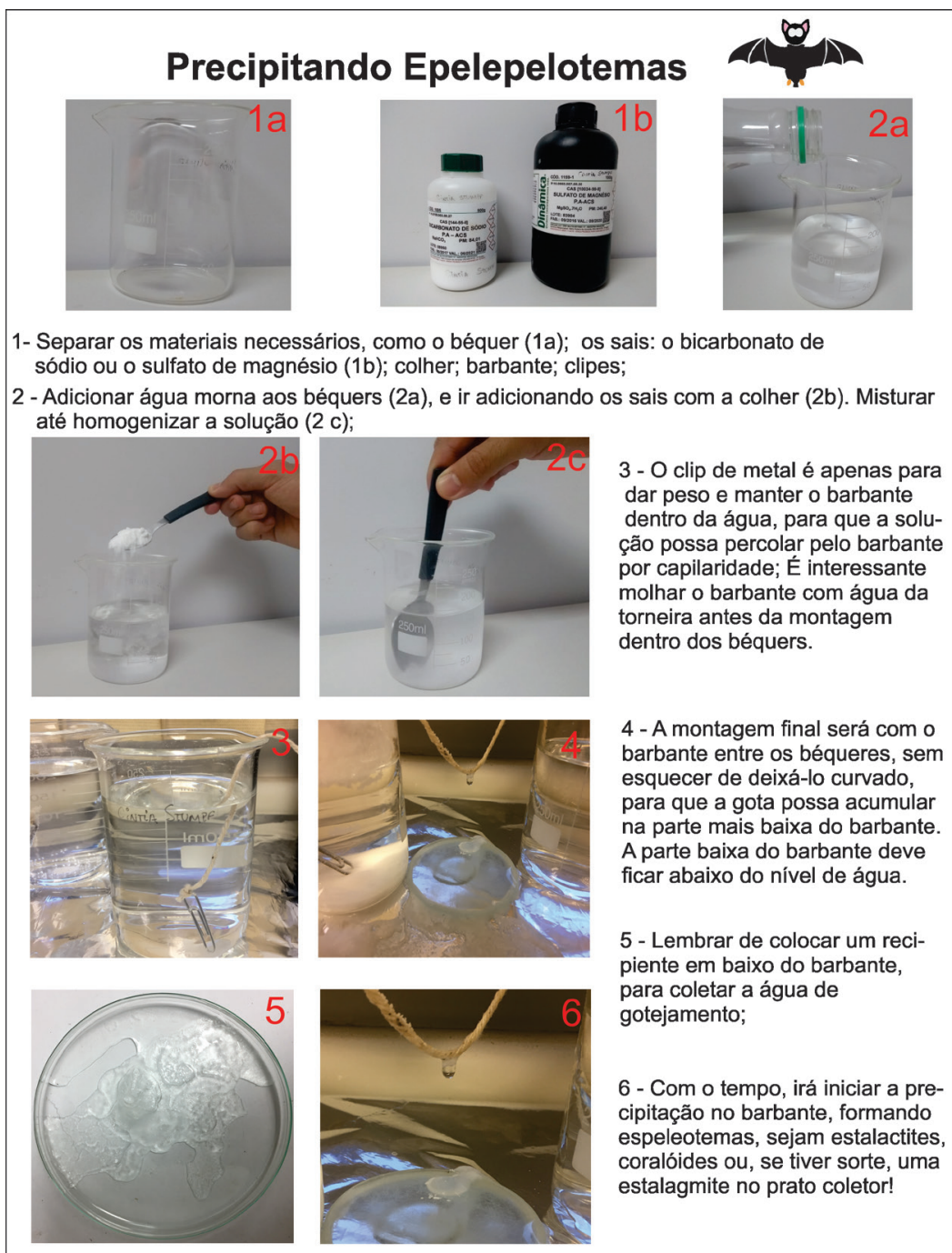

Figura 2. Os passos para realização do procedimento

de relógio entre os recipientes. Caso o fio esteja muito longo, pode ser necessário corta-lo para acertar o comprimento ideal.

O experimento com sal grosso foi realizado utilizando os mesmos princípios, porém uma metodologia um pouco diferente, ilustrado na figura 3. O sal grosso foi adicionado a um saco de TNT, material de tecido permeável, facilmente encontrado em papelarias. Devido à extrema solubilidade do sal de cozinha, ao introduzir água direto sobre ele, o mesmo irá dissolver completamente e ser transportado em solução junto com a água, precipitando-se apenas no pires coletor, formando cristais euédricos de sal (mineral halita, $\mathrm{NaCl}$ ). Para que haja a formação de estalactite, é adicionado sobre o sal um pouco de terra de jardim, para reter um pouco a água e promover a lenta dissolução do sal, permitindo assim a formação da estalactite.

Uma vez preparado à mistura de sal e terra, o saco foi amarrado próximo à torneira, para já realizar a adição de água. O saco pode ser afixado em qualquer lugar, desde que fique suspenso sobre o vidro de relógio e posas ser regado com água (figura 3).

O experimento deve ser montado em algum lugar calmo que evite vibrações e de preferência em algum local onde não haja exposição direta ao sol.

Evaporação intensa pode inibir a percolação do fluido pelo barbante, impossibilitando a cristalização do espeleotema, enquanto a vibração pode facilmente quebrar o material precipitado.

Os resultados obtidos podem variar dependendo das condições de temperatura e umidade do local onde o experimento é realizado. Observações diárias podem ser realizadas para descrever os avanços na cristalização do espeleotema, como o acompanhamento do nível da água restante nos béqueres e o crescimento do cristal.

Podem-se adicionar corantes nas soluções de sal para colori-las, de forma a tornar o experimento mais lúdico.

Após a realização do experimento, foram realizados registros fotográficos dos resultados macroscópicos. Os precipitados formados foram também observados e fotografados utilizando lupa binocular Leica modelo MZ12.

\section{Resultados e Discussões}

\subsection{Conceitos Preliminares}

Dependendo do nível de escolaridade, diferentes abordagens do conteúdo básico podem ser feitas. Minimamente, os seguintes conceitos devem 
ser dominados pelos professores ou indivíduos que proporcionaram a atividade aos alunos:

Os espeleotemas são formas rochosas encontradas no interior de cavernas, que se formam em seus tetos, paredes e pisos. Conforme a água da chuva infiltra pelo solo e rocha, se enriquece em $\mathrm{CO}_{2}$, o que a torna ácida e capaz de dissolver a rocha calcária. $\mathrm{O} \mathrm{CO}_{2}$ é um gás que está disponível na natureza e é fornecido para a água da chuva principalmente pela produção biológica nas raízes das plantas no solo e pela decomposição de matéria orgânica. Assim, ao percolar pelo solo, a água da chuva reage com o $\mathrm{CO}_{2}$ do solo, formando ácido carbônico, um ácido fraco, de acordo com a seguinte reação química:

$$
\mathrm{H}_{2} \mathrm{O}+\mathrm{CO}_{2} \rightarrow \mathrm{H}_{2} \mathrm{CO}_{3}
$$

Dessa forma, a água fica cada vez mais ácida, te. Para memorizar os nomes um tanto quanto esquisitos para as crianças, é comum relembrar que o " $T$ " de estalactite refere-se ao teto da caverna. Ambas as formações ocorrem pelo fluxo de água pela caverna, que dissolve a rocha e transporta íons, que se precipitam quando encontram condições específicas.

A água que goteja da estalactite fornece material para o chão da caverna, onde uma estalagmite pode ser formada. Dessa forma, estalactites e estalagmites são comumente encontradas em par, e podem até mesmo crescer até se encontrarem formando espeleotemas conhecidos como colunas.

\subsection{Experimento e Fatores de Influência}

O experimento foi realizado nas instalações da Universidade de Brasília. Apesar de haverem sido utilizados utensílios laboratoriais como béqueres, aumentando o potencial de dissolução da rocha que se encontra abaixo do solo. Muitas cavernas se formam em rochas carbonáticas, devido a facilidade de dissolução destas rochas frente a uma solução corrosiva. Ao penetrar pela rocha e encontrar a caverna, essa solução de água + ácido carbônico libera $\mathrm{CO}_{2}$ para a atmosfera da caverna, provocando a deposição de cristais que lentamente decoram as cavernas. Uma síntese destes processos é apresentada na figura 4.

Os espeleotemas podem ser compostos por diferentes minerais, mas comumente são formados por calcita $\left(\mathrm{CaCO}_{3}\right)$, mineral abundante e comum em cavernas calcárias. Espeleotemas de sal, como o precipitado no experimento aqui proposto, também ocorrem na natureza.

Estalactites e estalagmites são tipos de espeleotemas que se formam apontando para o chão e para o teto, respectivamen-

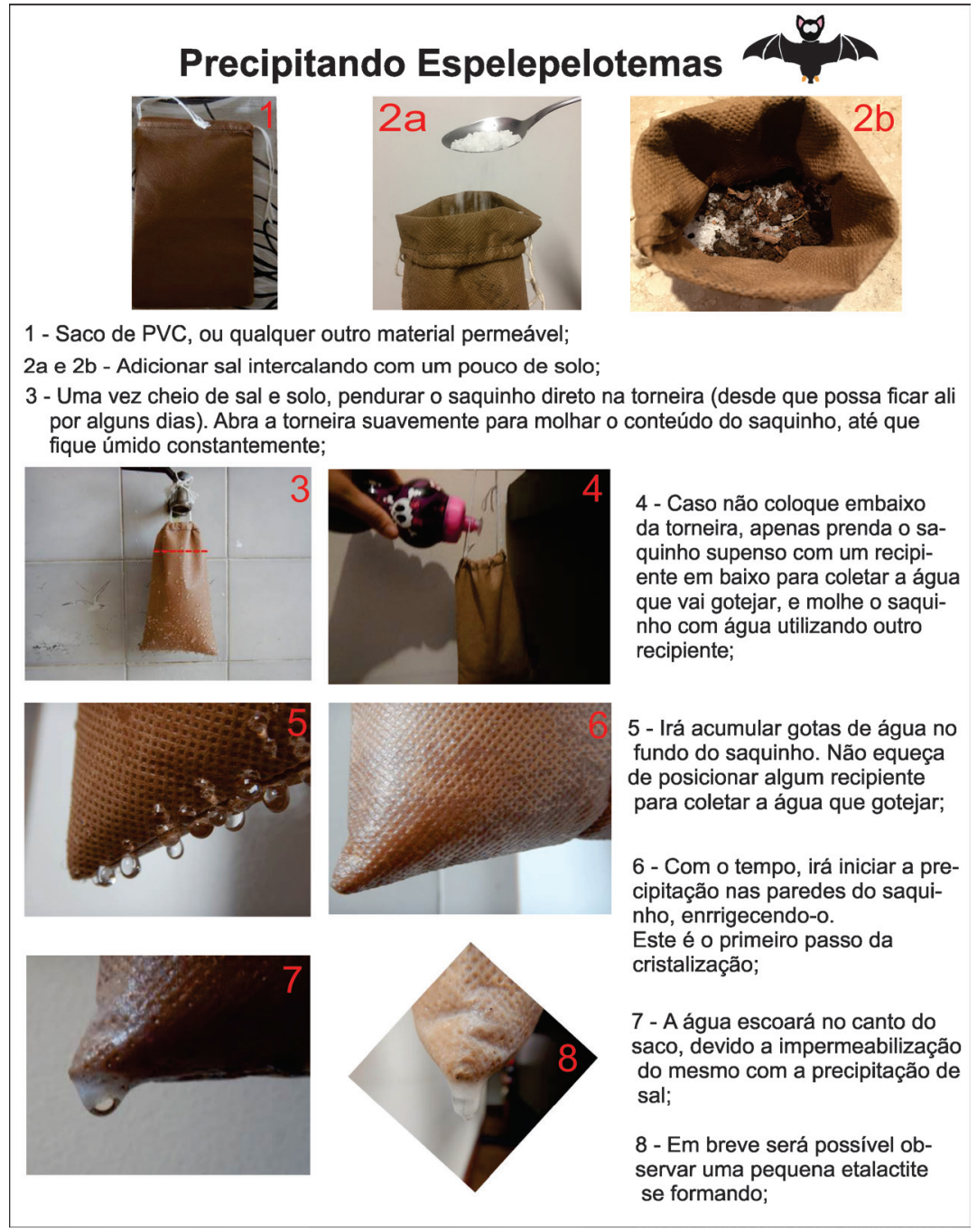

Figura 3. Procedimento ilustrativo do experimento, utilizando sal grosso para churrasco. Para mais detalhes consultar texto de Materiais e Métodos 
vidro de relógio e solutos químicos comprados, é possível realizar o mesmo experimento em condições de "laboratórios caseiros", utilizando materiais simples e facilmente encontrados como especificado na seção Materiais e Métodos.

Foram realizados experimentos utilizando três diferentes solutos: o sulfato de magnésio, bicarbonato de sódio e sal grosso de churrasco. O primeiro deles, sulfato de magnésio $\left(\mathrm{MgSO}_{4} \cdot 7 \mathrm{H}_{2} \mathrm{O}\right)$, também é conhecido como sal de Epsom, ingrediente de grande parte dos sais de banho, possível de se adquirir em diversas lojas de produtos naturais e ou lojas on line. O bicarbonato de sódio $\left(\mathrm{NaHCO}_{3}\right)$, é uma substância alcalina com diversas aplicações no dia-a-dia e facilmente encontrado em supermercados ou lojas de material

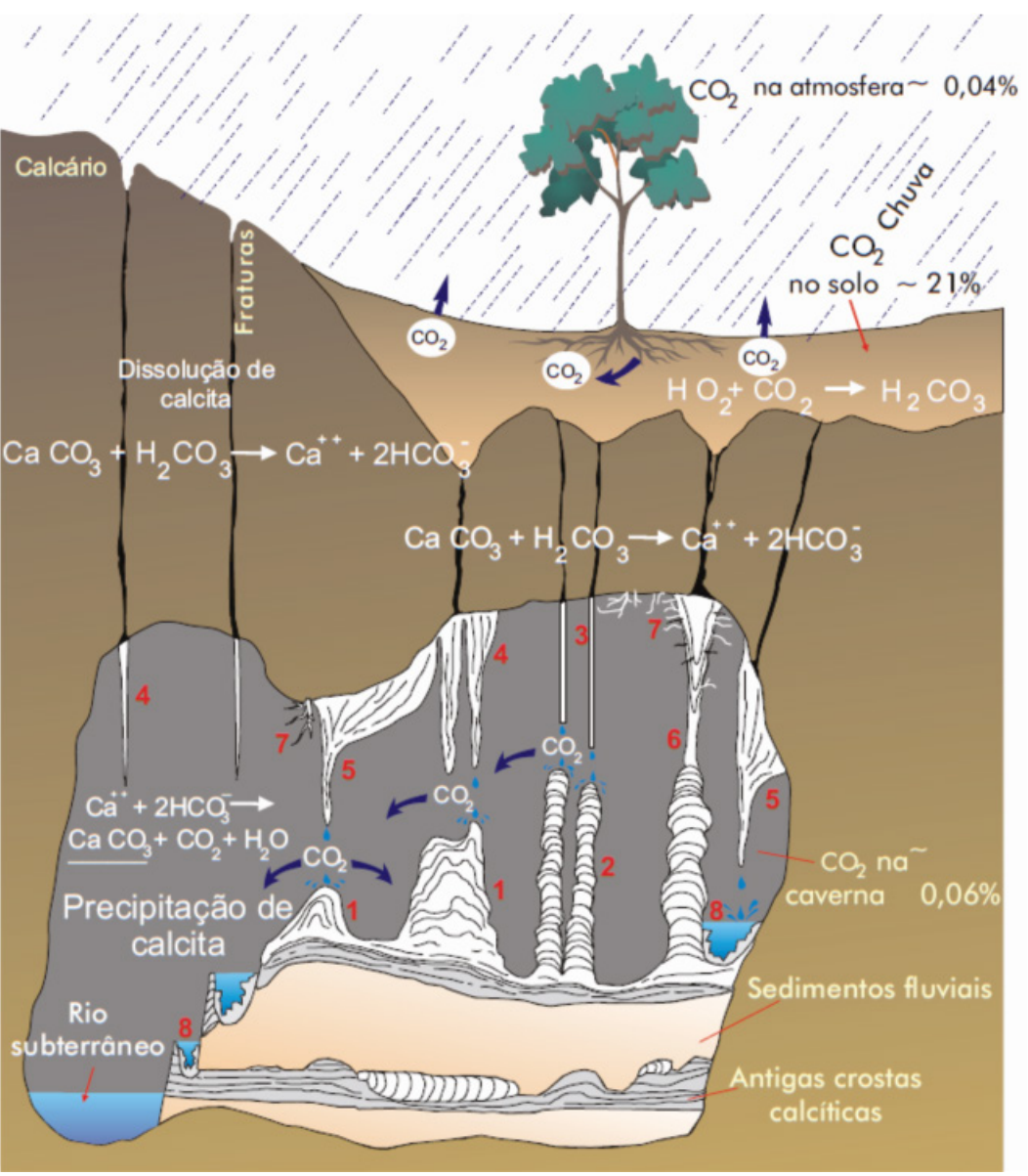

Figura 4. Esquema didático sobre a formação de diferentes tipos de espeleotemas e as reações químicas envolvidas no processo. Fonte: (Teixeira et al. 2000) de limpeza. Por fim, o mais simples dos solutos, sal grosso de churrasco, é encontrado em qualquer supermercado.

Após um dia do início do experimento já foi possível observar a formação incipiente do precipitado. No decorrer de cinco dias de observação, foi possível constatar a formação de espeleotemas, entre eles estalactite, estalagmite, coralóides, escorrimentos e marquises.

Além das formas macroscópicas que são facilmente observáveis a olho nu, os cristais precipitados foram observados com auxilio de uma lupa binocular. As imagens produzidas com a lupa podem ser compartilhadas e mostradas para os discentes. Contudo, os resultados macroscópicos já promovem a compreensão e elucidação sobre a formação de espeleotemas.

O uso de água quente aumenta a capacidade de dissolução dos sais na água; dessa forma é possível adicionar uma grande quantidade de soluto formando uma solução saturada. A quantidade de sal que será necessário adicionar irá depender do volume do recipiente utilizado para produzir a solução supersaturada. O ideal é adicionar sal até que se observe a formação de precipitado no fundo do recipiente.

O barbante molhado imerso na solução atua como um meio de transporte da solução pelo princípio da capilaridade, simulando a transmissão da solução pelo sistema epicárstico (carste acima da caverna). Ao percolar a solução pelo barbante, devido a efeitos de evaporação e supersaturação da solução, precipitados se formam ao redor do recipiente e no início do barbante, formando estruturas semelhantes aos coralóides encontrados abundantemente em cavernas (Figura 5).

Seguindo o caminho do barbante, quando o fluído encontra a parte mais baixa, a solução irá formar uma gota pela ação da gravidade e simular a formação de estalactite. Este seria um análogo para a água infiltrada pelo solo e rocha atingindo o teto da cavidade e entrando em contato com a atmosfera da caverna. Mesmo já havendo precipitado cristais de sal pelo caminho, a gota formada na ponta da

\begin{tabular}{c|c|c|c|c|c}
\hline (C) Terrae Didat. & Campinas, SP & v.14 & n.4 & p. 445-454 & out./dez. 2018 \\
\hline
\end{tabular}


estalactite ainda apresenta soluto em solução, assim, ao pingar no prato posicionado abaixo do barbante, pode ainda formar escorrimentos e até mesmo estalagmite (Figura 6).

Outra feição interessante observada foi a precipitação de placas de sal dentro dos béqueres, que marcam o nível da água dentro do recipiente antes que a solução fosse absorvida pelo barbante ou evaporada. Estas formações se assemelham a espeleotemas formados na superfície de lagos em cavernas, onde água supersaturada estagnada causa precipitação destes níveis próximos às paredes (Figura 7). Com a variação do nível d'água, estas placas de calcita podem ser expostas no espaço aéreo da caverna, formando um registro da variação do lençol freático.

As comparações entre os espeleotemas reais e os obtidos no experimento apresentadas nas figuras 5 , 6 e 7 servem como subsídio para elucidar as diferenças e semelhanças entre o modelo físico e a realidade, importante principalmente para os alunos impossibilitados de ir ao campo.

\subsection{Discussões Propostas para Alunos}

A partir dos resultados obtidos com o experimento, diversos temas podem ser discutidos com os alunos. Para embasar as discussões, é necessário que os alunos realizem observações sistemáticas do avanço do experimento, anotando detalhes sobre a velocidade e o crescimento

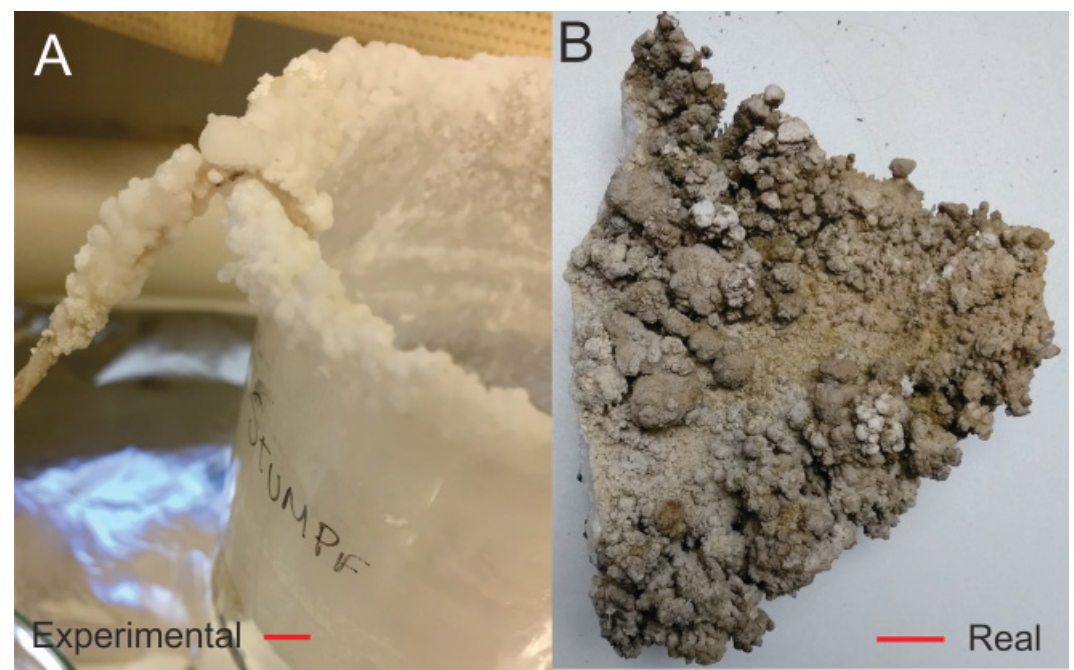

Figura 5. Formação de coralóides. Pode-se observar a semelhança entre o precipitado do experimento e espeleotema real formado em cavernas. A barra vermelha representa $1 \mathrm{~cm}$ para referência. A) Precipitados da solução de bicabornato de sódio. B) Coralóides da Caverna Tamboril (MG). Fotos dos autores

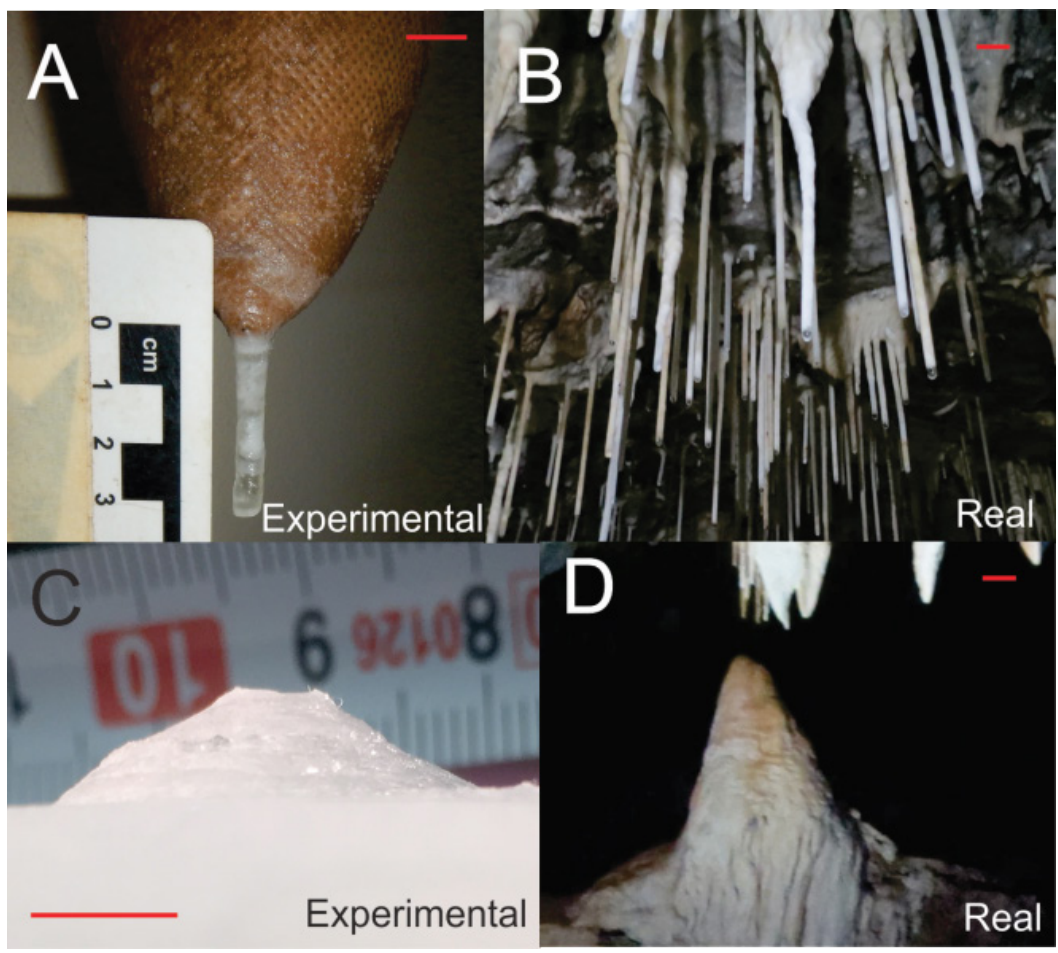

Figura 6. Formação de estalactite e estalagmite. A) Estalactite de sal grosso com aproximadamente $3 \mathrm{~cm}$ de comprimento. B) Estalactites ativas precipitando a partir do teto da caverna. Interessante notar que tanto A como B ainda apresentam o interior vazio, por onde a gota pode circular até a ponta, já que o mineral se precipita apenas ao redor das gotas, construindo as paredes da estalactite. Nesta situação inicial de formação de estalactite, o espeleotema recebe o nome de "Canudo" (sodastraw) devido à semelhança com o utensílio. C) Estalagmite de sulfato de magnésio com aproximadamente $1 \mathrm{~cm}$ de altura. D) Estalagmite precipitada sobre bloco. Barras vermelhas para referência equivalem a $1 \mathrm{~cm}$. Fotos reais da Caverna das Rãns (TO). Fotos dos autores 
dos espeleotemas de sal. Propõe-se as seguintes discussões:

A) Como o experimento se assemelha a formação de espeleotemas em cavernas?

Esta discussão pode ser aberta para analisar a capacidade dos alunos de aplicarem e compararem um modelo teórico à realidade. O professor responsável deve guiar a discussão de forma a garantir que sejam abordadas questões

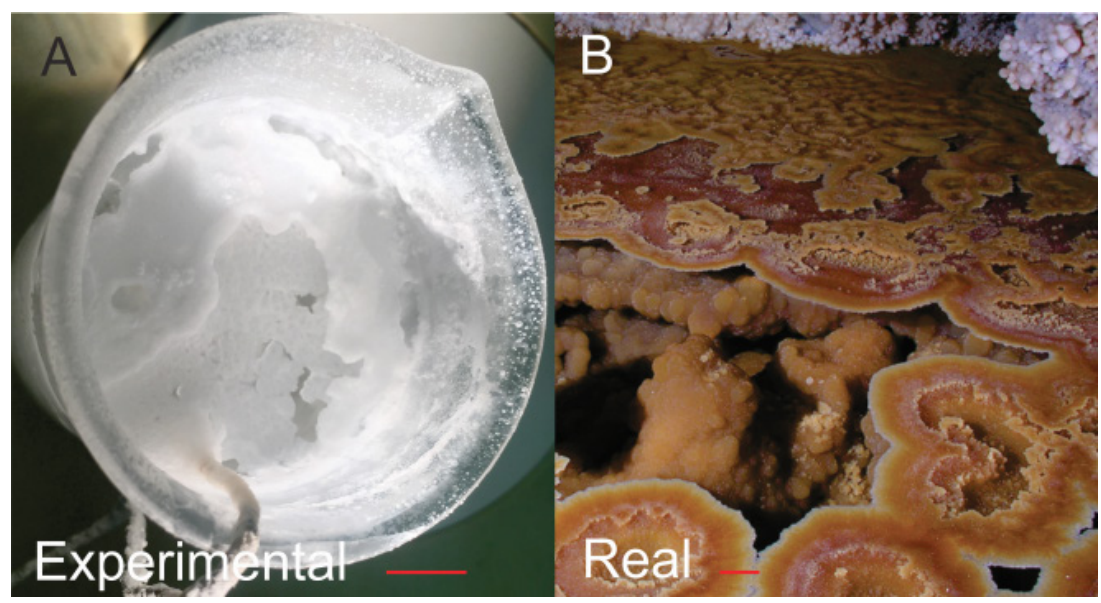

Figura 7. Formação de prateleiras de pedra. A) Prateleiras formadas dentro do béquer, indicando variação do volume de solução. B) Prateleiras da Caverna Lechugilla, New Mexico, EUA. Fonte: http://www.cavepics.com/ referentes às diferenças da produção da solução saturada na natureza com a solução produzida com sal. Na natureza, a geração de tal solução é mais complexa, pois depende de inúmeros fatores, como a disponibilidade de água de chuva, cobertura vegetal da superfície, produção biológica do solo para acidificação das águas e dissolução da rocha carbonática para saturar a água com íons.

B) Quão rápido se formam os espeleotemas? $\mathrm{Na}$ natureza, os espeleotemas calcários se formam com a mesma rapidez que os espeleotemas de sal do experimento?

A velocidade de crescimento dos espeleotemas depende da velocidade com que a água da chuva penetra pelo solo e rocha acima da caverna, de quão ácida é a água da chuva ao encontrar com a rocha, e quanto $\mathrm{CO}_{2}$ tem na atmosfera da caverna. Apesar das variáveis envolvidas no processo de crescimento de espeleotemas na natureza, eles não crescem em uma taxa constante. Mudanças climáticas no decorrer do tempo afetam o crescimento dos mesmos. O professor pode expor aos alunos exemplos brasileiros, onde a taxa de crescimento dos espeleotemas pode ser menores que um $\mathrm{mm}$ por ano ( $1 \mathrm{~mm} / \mathrm{ano})$ (Bernal et al. 2016, Stríkis et al. 2011)

C) Qual o impacto que o ser humano pode causar nos espeleotemas?

Quando ocorre desmatamento acima da caverna, menos água é retida no solo, influenciando a quantidade de água que infiltra para a caverna, reduzindo o potencial de geração de ácido carbônico e acidificação da água, podendo afetar a formação dos espeleotemas. Os espeleotemas são formações muito delicadas e podem ser facilmente quebrados quando tocados inapropriadamente. Infelizmente é comum ver impactos em cavernas, onde espeleotemas foram quebrados e removidos das cavernas para serem vendidos ou levados como lembrança, demonstrando exemplos vivos de depredação do ambiente cavernícola.

D) Porque devemos preservar os espeleotemas e as cavernas?

É possível observar a fragilidade destas formações com os resultados do experimento (Figura 8). Além da fragilidade intrínseca de alguns tipos de espeleotemas, eles podem demorar milhares ou até mesmo milhões de anos para se formarem na natureza. Como seu crescimento pode variar no decorrer do tempo, caso alguma formação sofra dano, não irá necessariamente se formar o mesmo espeleotema novamente, dado que as condições ambientais da superfície e do interior da cavidade podem ter sido alteradas no decorrer do tempo geológico.

\subsection{Testando com alunos universitários}

Este experimento foi aplicado para alunos do primeiro semestre do curso de Geofísica da UnB e integrantes do Grupo de Espeleologia da Geologia da UnB (Gregeo). Apesar de ter sido elaborado pensando em um público de nível fundamental de educação, o resultado com estes alunos universitários foi muito positivo. Eles demonstraram bastante interesse e curiosidade. Com o intuito de avaliar o experimento, foi realizada uma roda de conversa com os participantes ao final da atividade. Ficou evidente a carência de atividades práticas nas escolas brasileiras, pois para a maioria dos participantes foi o primeiro contato com atividades práticas de 
modelagem de processos físicos. Por esta razão acredita-se na importância da divulgação deste material.

\section{Próximos Passos}

Este experimento foi realizado apenas nas dependências da Universidade, sendo necessária uma etapa posterior de aplicação da atividade prática para diferentes públicos. Pretende-se avaliar qual o melhor e mais adequado público

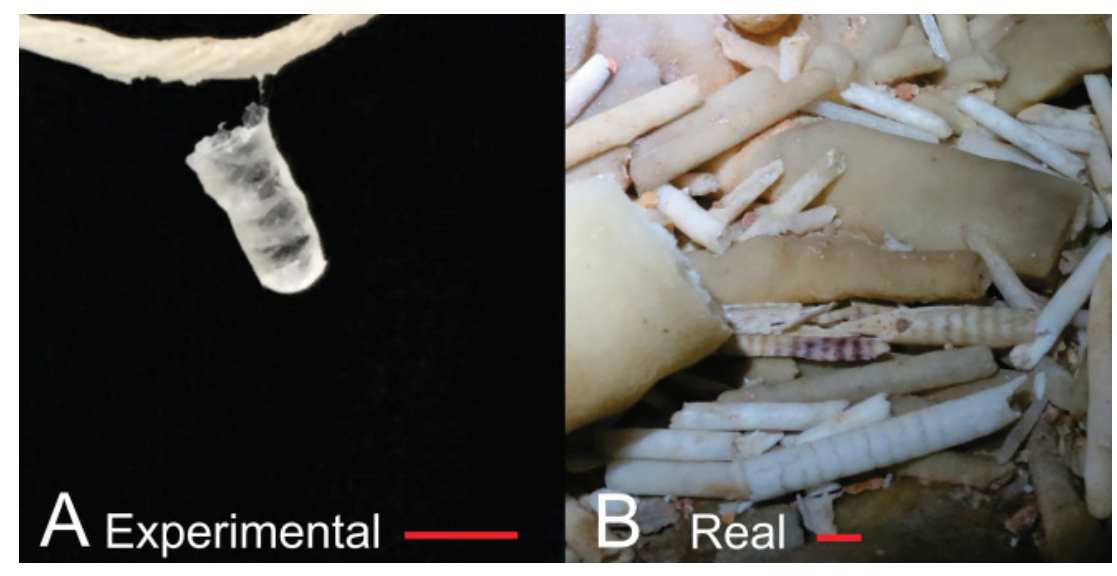

Figura 8. Espeleotemas danificados/quebrados. A) Devido à vibração no local de realização do experimento, a incipiente estalactite rompeu na base que a fixava ao barbante, comprometendo a continuidade do seu processo de crescimento. B) Exemplo real de estalactite e canudos quebrados, acumulados no chão da cavidade. Danos irreversíveis. Caverna São Mateus (GO). Foto dos autores alvo, e local para aplicação de tal atividade. Julga-se também importante avaliar o interesse despertado nos participantes, o que pode ser feito por meio de conversas e aplicação de questionários, para detectar os pontos fracos e fortes da prática experimental.

Também é importante avaliar a organização das oficinas para realização da atividade e a capacidade de efetivação da proposta em sala de aula. É proposto também realizar um jogo com perguntas e respostas para consolidação do conhecimento.

\section{Conclusão}

Este trabalho apresenta uma contribuição para inclusão de experimentação prática no ensino de geociências, que pode ser aplicado a diferentes níveis escolares, desde ensino fundamental ao nível superior.

Percebe-se a pouca disponibilidade de guias práticos em português que fomentem o desenvolvimento de atividades extra-curriculares que englobem diferentes conceitos do ensino formal como química e geografia.

A espeleologia é um campo do saber que fornece possibilidade de abordar diversos conteúdos de forma multidisciplinar, envolvendo diferentes áreas do conhecimento. A formação de espeleotemas, como proposto no experimento aqui apresentado, abrange apenas uma pequena parcela do que pode ser encontrado no mundo subterrâneo. As cavernas fazem parte da história do homem desde os primórdios, sendo local onde se encontram diversos achados históricos, arqueológicos e paleontológicos. Os espeleotemas cobrem apenas parte da compreensão geológica destes ambientes.

Acredita-se que iniciativas como a proposta no presente trabalho contribua para a preservação destes ambientes, que são comumente vítima de impactos ambientais, como acúmulo de lixo, contaminação de águas subterrâneas, depredação de seu entorno e interior. Dessa forma, o experimento pode contribuir não somente como introdução a metodologia científica nas escolas, como também de educação ambiental.

\section{Agradecimentos}

Agradecemos a revisão e comentários feitos por Luciana Figueiredo Prado que contribuíram para o presente trabalho, assim como a Eduardo B. de Carvalho pelas observações e sugestões para melhor realização do experimento. Agradecemos também os membros do GREGEO pela participação no experimento e aos comentários feitos pelos revisores, que muito agregaram a nossa compreensão de como elaborar um trabalho para publicação e que melhoraram este manuscrito.

\section{Referências}

Almeida C.N., Araújo C, Mello E.F. 2015. Geologia nas Escolas de Ensino Básico : a experiência do Departamento de Geologia da Universidade Federal do Rio de Janeiro. Terra Didatica. 11(3):150-161. URL: http://www.ige.unicamp.br/ terraedidatica/. Acesso 07.09.2018. 
Bernal J.P., Cruz F.W., Stríkis N.M., Wang X., Deininger M., Catunda M.C.A., Ortega-Obregón C., Cheng H., Edwards R.L., Auler A.S. 2016. High-resolution Holocene South American monsoon history recorded by a speleothem from Botuverá Cave, Brazil. Earth and Planetary Science Letters, 450(1):186-196. DOI: 10.1016/j.eps1.2016.06.008.

Carlsbad Caverns. s.d. Caves, Canyons, Cactus \& Critters. A curriculum and activity guide for Carlsbad Caverns National Park. Middle School Geology. In: National Park services education. URL: https:// www.nps.gov/cave/learn/education/upload/geology_middle_school.pdf. Acesso07.09.2018.

Carneiro C.D.R., Toledo M.C.M.de, Almeida F.F.M.de. 2004. Dez motivos para a inlcusão de temas de geologia na educação básica. Rev. Bras. Geoc., 34(4):553-560. URL:http://www.ppegeo.igc.usp. br/index.php/rbg/article/viewFile/9787/9135. Acesso 07.09.2018.

Cave Pics Home Page. 2018. URL: http://www.cavepics. com/. Acesso 25.09. 2018.

Custódio R.P., Dantas M.A.T., Prata A.P.N. 2012. O uso de recursos didáticos e a Espeleologia : Reflexões sobre alternativas para ensinar Ciências e Biologia. In: Colóq. Intern. "Educ. e Contemporaneidade", 6, São Cristovão, SE/Brasil. v. 6, p. 1-13. Anais.... URL: http://educonse.com.br/viicoloquio/publicacao_eixos.asp. Acesso 07.09.2018.

EGRIC. Espeleo Grupo Rio Claro. 2011. Noções básicas de espeleologia. Apostila Didática.

Fairchild I.J., Baker A. 2012. Speleothem Science: From
Process to Past Environments. Wiley-Blackwell. DOI: 10.1002/9781444361094. Acesso 07.09.2018.

Ferreira R.L., Gomes F.T.M.C., Silva M.S. 2008. Uso da cartilha "Aventura da vida nas cavernas" como ferramenta de educação nas atividades de turismo em paisagens cársticas. Pesq. Tur. e Paisag. Cársticas, 1(2):145-164. URL: http://www.cavernas.org.br/ ptpc/ptpc_v1_n2_145-164.pdf. Acesso 07.09.2018.

Geze B., Ribera A. 1968. La espeleología científica. Ed. Martínez Roca.

Hance T., Befus K.M. 2015. Speleothems and sand castles. Sci. Child. 53(2):36-41. URL: https:// s3.amazonaws.com/nstacontent/sc1502_36.pdf?AWSAccess KeyId = AKIAIMRSQAV̄7P6X4QIKQ\&Expires $=1536414798 \&$ Signature $=\mathrm{s}-$ bE5iEnCMWo3vHUEL8PzeCxbAdQ\%3d. Acesso: 07.09.2018.

Moore G.W. 1952. Speleothem: a new cave term. National Speleological Society News, 10(6):2.

National Park Service. n.d. Growing Speleothems.

Stríkis N.M., Cruz F.W., Cheng H., Karmann I., Edwards R.L., Vuille M., Wang X., Paula M.S.de, Novello V.F., Auler A.S. 2011. Abrupt variations in South American monsoon rainfall during the Holocene based on a speleothem record from central-eastern Brazil. Geology 39:1075-1078. URL: https://doi.org/10.1130/G32098.1. Acesso 07.09.2018.

Teixeira W., Toledo M.C.M.de, Fairchild T.R., Taioli F. 2000. Decifrando a Terra. São Paulo: Oficina de textos. 